\title{
Globe
}

Revue internationale d'études québécoises

\section{Paul Chamberland : En nouvelle barbarie. Essais. Montréal, l’Hexagone, 1999}

\section{Maxime Prévost}

Volume 6, numéro 1, 2003

URI : https://id.erudit.org/iderudit/1000701ar

DOI : https://doi.org/10.7202/1000701ar

Aller au sommaire du numéro

Éditeur(s)

Globe, Revue internationale d'études québécoises

ISSN

1481-5869 (imprimé)

1923-8231 (numérique)

Découvrir la revue

Citer ce compte rendu

Prévost, M. (2003). Compte rendu de [Paul Chamberland : En nouvelle barbarie. Essais. Montréal, l'Hexagone, 1999]. Globe, 6(1), 180-182.

https://doi.org/10.7202/1000701ar d'utilisation que vous pouvez consulter en ligne.

https://apropos.erudit.org/fr/usagers/politique-dutilisation/ 


\section{REVUE INTERNATIONALE D'ÉTUDES QUÉBÉCOISES}

photographie de la couverture nous fournit un élément de réponse : elle donne à voir une rangée de manifestants regroupés sous le mot d'ordre plus festif que contestataire - "vive la nation québécoise "; "quelques jeunes gens souriants, écrit Pleau lui-même, qu'on croirait être des collégiens surpris en plein chahut ; et quelques autres plus tranquilles, qui tâchent sans trop de succès de se donner un air menaçant " (p. 113, je souligne). Pourquoi donc chercher à décaper l'image d'une Révolution tranquille pour mettre à sa place celle d'une "Révolution québécoise " franchement juvénile, sympathique, souriante et dérisoirement menaçante? La "relecture * a-t-elle vraiment lieu? Non seulement l'ouvrage de Pleau reconduit-il le cliché d'une révolution on ne peut plus tranquille, mais il ne semble pas contredire, en définitive, le travail de deuil contemporain dont est l'objet la pensée révolutionnaire, voire la révolution tout court.

Martin Jalbert

Université Laval

\section{Paul Chamberland}

\section{En nouvelle barbarie. Essais}

Montréal, l'Hexagone, 1999.

Cette collection d'essais de Paul Chamberland s'inscrit - son titre l'annonce d'emblée - dans le vaste réseau de ces textes qui entendent diagnostiquer la société contemporaine : la "nouvelle barbarie * dont il est question se veut héritière de la "société du spectacle " de Guy Debord et de la "fabrique du consentement " de Chomsky et Herman (deux notions évoquées au passage, dans "Malaise généralisé *, p. 27). Elle affiche aussi un air de famille avec la *festivocratie" de Philippe Muray, l'" horreur économique " de Viviane Forrester, l' ère du vide * de Gilles Lipovetsky, la "défaite de la pensée "d'Alain Finkielkraut et le " devoir de bonheur " de Pascal Bruckner : autant de constats alarmistes (et parfois alarmants) sur l'état de notre civilisation fin-de-siècle. Par conséquent, le premier défi qui s'impose à l'auteur d'un tel ouvrage est d'éviter de prêcher pour les seuls convertis. Défi que Paul Chamberland ne relève que partiellement.

L'unité du recueil est assurée par la chronique éparse de "l'avancée du non-humain, ou de l'immonde (le non-monde) " ("Sujet citoyen ", 
p. 132), cet immonde étant défini ailleurs comme al'instrumentalité gestionnaire et économiste * ( "Le poète et le citoyen •, p. 164). Les textes réunis sont de longueurs inégales (de quelques lignes à une dizaine de pages) et tiennent davantage de l'instantané d'écriture, voire du poème en prose, que de l'essai argumentatif. Du coup, le lecteur pourra être charmé par cette heuristique proprement littéraire qui cherche à cerner et définir une réalité plus qu'à convaincre par argumentation (nul doute que ces essais miniatures doivent en partie leur publication au prestige de leur signature). Ce concept - vaste - de nouvelle barbarie incitera certains lecteurs à croire que Chamberland trop embrasse; mais le fait demeure qu'il parvient à saisir quelques phénomènes, fugitifs, qui échappent à la plupart des moralistes actuels. Par le fait même, il parvient subtilement à façonner le regard de son lecteur. Par exemple, le titre "Le mensonge a été normalisé "sera accueilli avec scepticisme par les lecteurs de Guy Debord, qui craindront de voir ressassé l'argumentaire du "faux sans réplique ", sans que la redite ne s'accompagne d'une nouvelle révélation; or, la lecture de cette phrase les rassurera sans doute : "Qui ne ment pas aujourd'hui est tout simplement tenu pour un idiot ou un extraterrestre ; il est, de fait, ostracisé " (p. 22). Le ton est donné : l'écriture puise sa source dans l'observation concrète, dans la " chose vue * bien notée qui donne à l'ensemble une indéniable valeur documentaire tant pour les contemporains que pour les lecteurs de demain ("Je vais consacrer ma journée à me déplacer, m'intoxiquant du spectacle des affairés, des mufles, des faces de carême et des mâchoires barrées ", "Simple fiction ", p. 115).

Une fois que l'acuité du regard, l'honnêteté du propos et la rigueur du style de Paul Chamberland ont commencé à opérer leur charme, le fureteur trouvera une foule de traits notables, frappants par leur précision, bien que cette accumulation puisse sembler gratuite, capricieuse, chaotique: "Mode d'être contemporain : antiérotique mais pervers, le monadisme prédateur " ("Entre collègues", p. 56). À son meilleur, le poète parvient à redéfinir l'évidence, à force de définitions simples, astucieuses et surprenantes. Qu'est-ce que la vulgarité? Réponse : "La franche satisfaction à ignorer l'autre " "Athéisme vulgaire ", p. 83). Qu'est-ce que la langue de bois? C'est la "langue de la totalité gestionnaire *, dont le principe se définit par deux traits : "l'altération, ou la falsification, du référent; la prise en otage du destinataire " ( Le poète et le citoyen ", p. 164-165). 
L'intérêt premier de cette collection de textes ne relève pas foncièrement du logos, ni même du pathos lyrique auquel l'auteur ne se refuse guère ("Le réel a pris l'aspect du rictus de Dieu ", "Âge de fer ", p. 49), mais plutôt d'une qualité qui - Chamberland nous aide à le comprendre - se fait rarissime : le refus du cynisme.

Maxime Prévost McMaster University

\section{Joseph Yvon Thériault}

Critique de l'américanité.

Mémoire et démocratie au Québec

Montréal, Québec Amérique, 2002.

\section{Donald Cuccioletta, Jean François Côté et Frédéric Lesemann (dir.)}

Le grand récit des Amériques

Québec, Presses de l'Université Laval, 2001.

\section{Donald Cuccioletta (dir.)}

\section{L'américanité et les Amériques}

Québec, Presses de l'Université Laval, 2001.

Au cours des dernières décennies, de nombreux ouvrages consacrés à l'américanité sont parus au Québec. Parmi les plus récents, notons celui de Joseph Yvon Thériault, Critique de l'américanité : mémoire et démocratie au Québec, dans lequel nous trouvons une des premières tentatives visant à commenter l'ensemble de cette production. L'auteur souligne, dans un premier temps, la contradiction inhérente au discours gravitant autour de l'américanité; en effet, elle semble devoir être présentée à la fois comme une pensée forte, en raison du réalignement tant politique que culturel du Québec vers les États-Unis qu'elle semble impliquer, et comme une pensée molle en raison de son caractère d'évidence. Thériault développe l'idée de l'américanité comme pensée forte, révélatrice d'une impasse dans le cheminement identitaire de la 